\title{
CONFLITOS SOCIAIS E SÓCIO-AMBIENTAIS: PROPOSTA DE UM MARCO TEÓRICO E METODOLÓGICO
}

\author{
Social and environmental conflicts: a theoretical and \\ methodological framework proposal
}

Gloria Maria Vargas

Doutora Pesquisadora associada do Centro de Desenvolvimento Sustentável (CDS) da Universidade de Brasília yoya@unb.br

Artigo recebido para publicação em 16/04/2007 e aceito para publicação em 16/08/2007

RESUMO: Apresenta-se uma proposta de abordagem teórica e metodológica para a análise e manejo de conflitos sociais em geral, que pode ser aplicado nos casos dos sócio-ambientais, assim como algumas características particulares destes últimos. Realiza-se uma releitura do tema baseada na bibliografia consultada, enfatizando as estratégias de abordagem e as conceituações dos conflitos que as alimentam. Vinculam-se de forma explícita e sistemática os supostos teóricos que dão embasamento a estas abordagens e às formas de compreender os conflitos e utilizamse para propor um modelo de compreensão e manejo dos conflitos.

Palavras-chave: Conflitos sociais; Conflitos sócio-ambientais; Gestão de conflitos.

ABSTRACT: A theoretical and methodological approach to social conflict management and analysis that can be applied to environmental conflicts is presented, as well as a set of specific environmental conflict characteristics. Based on the bibliography analysed, the topic is revisited stressing the different approach strategies used and the conceptualizations on conflicts that stem from them. The theoretical background that support these approaches and the ways conflicts are understood are used in order to propose a framework to understand and deal with social and environmental conflicts.

Keywords: Social conflicts; Environmental conflicts; Conflict Management.

\section{INTRODUÇÃO}

Os conflitos são consubstanciais à historia da humanidade e seu estudo remonta a formação de escolas de pensamento na Grécia Antiga. Campos do conhecimento tão diversos como a Psicologia Social, a Economia, a Administração, a Sociologia, a
Antropologia e a Ciência Política têm-se ocupado do seu estudo.

Hoje se reconhece uma grande variedade de visões, abordagens e conceituações sobre os conflitos. Como é de se supor, isto traz enormes desafios para a tarefa de organizar esta temática mediante um ou 
vários princípios teóricos. Além de se observar uma relação frágil entre teoria, pesquisa e prática há muita imprecisão nos conceitos, o que estimula uma polissemia preocupante entre os termos utilizados na sua abordagem.

A primeira imprecisão achada ao estudar os conflitos é a forma como se denomina o campo de trabalho. É muito comum encontrar sinonímias entre gestão, resolução e transformação de conflitos. De igual forma, o termo mediação é utilizado muitas vezes no lugar de negociação, ou inclusive, se confunde com as técnicas específicas utilizadas nos processos de negociação. Pode-se dizer, portanto, que a falta de uniformidade na terminologia utilizada é mais a norma que a exceção. O termo mais comum na bibliografia revisada é o de "gestão de conflitos"1, que se utiliza como conceito guarda-chuva e indica, na maioria das vezes, uma abordagem genérica. Como os supostos teóricos são raramente explícitos, os casos têm de ser estudados um por um, para descobrir qual o entendimento que os autores fazem da terminologia usada.

Uma outra questão que pode ser salientada é a pouca quantidade de síntese do estado da arte, o que explica que existam poucas resenhas bibliográficas sobre a produção acadêmica ou profissional da área e poucos livros ou artigos que introduzam o tema desde um ponto de vista teórico. A literatura, em sua enorme maioria, é mais de tipo técnico, onde são expostos métodos e casos de gestão, resolução e/ou transformação de conflitos, sem que estes sejam explicitamente referidos às matrizes teórico-conceituais de onde partem os métodos utilizados e as visões sobre os casos estudados. Em geral, as metodologias são utilizadas com uma visão causalindutiva na qual, a partir das particularidades dos casos estudados, se inferem generalizações a serem comprovadas e aplicadas em outros casos. Isto dificulta a análise já que essas generalizações não são explicitadas e analisadas segundo uma linha teórico-conceitual conhecida.

O que leva à escolha de uma ou outra metodologia é o sucesso comprovado dos casos nos quais tenha sido aplicada, no entendimento tácito de que é uma área que não precisa de teorização, apenas de êxito empírico. Assim, muita da bibliografia aparece na forma de manuais, guias e receituários que oferecem regras ou instruções para exercícios de manejo exitosos.

Isto dificulta enormemente a construção de uma tipologia compreensiva que considere o amplo universo de literatura disponível nos níveis ideais de qualquer pesquisa: dos referenciais teóricos, passando pelas metodologias e técnicas aplicáveis até chegar aos estudos de caso.

É de se anotar que a maior parte da literatura se encontra em inglês, o que confirma a hegemonia anglo-americana no tema. A literatura em espanhol refere-se a grupos particulares que têm adotado algumas das técnicas desenvolvidas nos países anglófonos e que se aplicam em geral sem a explicitação dos referenciais teóricos e os porquês das escolhas das estratégias de manejo. ${ }^{2}$

A literatura em português é escassa, existindo alguns autores que enfatizam uma abordagem mais sociológica dos conflitos (NASCIMENTO, 2001), outros utilizam a visão da Ecologia Política para trabalhar a temática (ASCELRAD, 2001; FARIA, 1999; FUKS, 1998; LITTLE, 2001), e outros ainda, introduzem o tema no contexto da história dos movimentos ambientalistas (ALONSO e COSTA, 2002). Barbani Jr (2002) faz um esforço mais analítico, estabelecendo algumas categorias de classificação baseado em arquétipos sociológicos para depois particularizar no caso dos conflitos sócio-ambientais.

Neste artigo nos propomos realizar uma releitura do tema baseada na bibliografia consultada,

\footnotetext{
1 Em inglês, conflict management. Este termo tem suas limitações na medida em que exclui aproximações que vão além da "gestão", como no caso da transformação dos conflitos.

2 A rede Mesoamericana, a Chilena, a Peruana, etc.
} 
enfatizando as estratégias de abordagem e as conceituações dos conflitos que as alimentam. $\mathrm{O}$ intuito é vincular de forma explícita e sistemática os supostos teóricos que dão embasamento a estas abordagens e às formas de compreender os conflitos e, com isto, utiliza-las nos casos empíricos estudados em oficinas de gestão de conflitos realizadas em duas regiões da amazônia brasileira, o Portal da Amazônia em 9,10 e 11 de Agosto de 2006 e no Pará (Santarém e Itaituba) em 29, 30 e 31 de Agosto de 2006, no contexto do Projeto "Building Consensus on Access of Natural Resources in Brazilian Amazon - Projeto Diálogos" financiado pela União Européia e gerido por um consórcio de instituições, dentre elas, pelo Centro de Desenvolvimento Sustentável da Universidade de Brasília, a WWF e o CIRAD.

A partir deste exercício, espera-se contar com um instrumental teórico validado empíricamente que poderá ser utilizado em diferentes estudos de caso de como se lidar com os conflitos sociais e sócioambientais.

\section{Primeiras abordagens}

Até muito recentemente, a pesquisa e a compreensão dos conflitos oscilava entre duas visões, a primeira das quais entendia os conflitos como produto de situações estruturais da sociedade, e a segunda como produto da percepção das partes envolvidas. Elas são frequentemente enunciadas como as visões objetivista e subjetivista, respectivamente.

A perspectiva objetivista procura as origens dos conflitos na situação político-social e na estrutura da sociedade. Neste caso, o conflito pode existir independentemente das percepções das partes envolvidas no mesmo. É o caso dos conflitos de classe, que continuam existindo independentemente da percepção dos envolvidos e nos quais não se trata de que as diferentes classes têm objetivos incompatíveis e se disputem entre elas, senão de que a estrutura social é de tal forma, que os ganhos de uma das classes são as perdas de outra. (SCHMID, 1997). É também o caso dos conflitos como entendidos pela Ecologia Política (ASCELRAD, 2001). Já a perspectiva subje- tivista procura as explicações dos conflitos na percepção e incompatibilidade de objetivos entre as partes envolvidas.

Como é de supor, esta abordagem cria uma separação e uma dicotomia entre condições estruturais e percepções, desconhecendo que na maioria dos casos as duas situações fazem parte da dinâmica dos conflitos. Portanto, qualquer tipologia construída tendo como base esta distinção será insuficiente para captar todos os matizes de uma situação conflituosa. Parte da arte da negociação está justamente em construir pontes entre estas duas visões, o que vai depender das estratégias de gestão implementadas mediante o trabalho de facilitação, de negociação, etc.

Para superar a perspectiva dicotômica desta visão, alguns autores propõem compreender o conflito como conseqüência de uma ou uma combinação das seguintes possibilidades (DAHRENDORF, 1957; WEBER, 1948; Simmel, 1955 apud REIMANN, 2004):

- O conflito inserido nos assuntos da sociedade, porém, sem que se questione o sistema de poder e, portanto, entendido como conseqüência de percepções diferentes do status quo (assemelha-se à visão subjetivista).

- Como uma forma de luta não violenta para adquirir direitos e justiça social.

- Como catalisador da mudança social.

No primeiro caso, ao omitir relações de poder e opressivas da análise, esta visão pode estar incentivando indiretamente a reprodução destas relações. Por outro lado, uma visão que considere o conflito apenas como forma de procura de transformações dentro da sociedade, sem paralelamente manter um sentido de permanência, ordem e continuidade social, pode levar a situações de anarquia (REIMANN, 2004).

Pela bibliografia consultada, pode-se afirmar que os modelos e metodologias usadas se baseiam 
em uma ou várias combinações destas três visões. No entanto, o que deve ser enfatizado é que a forma de compreender o conflito leva às formas determinadas de manejo. Assim, podemos distinguir entre três formas diferentes de manejo dos conflitos segundo as estratégias escolhidas para se lidar com eles. São elas, a Gestão de Conflitos, a Resolução de Conflitos e a Transformação de Conflitos. Analisemos cada uma delas em detalhe.

\section{Gestão de Conflitos}

Esta abordagem entende o conflito como produto de diferentes percepções, valores e interesses das comunidades ou grupos envolvidos. Este tipo de enfoque está muito permeado pela visão manegerialista, e em termos teóricos está subvencionada por uma visão realista do comportamento dos atores a partir da teoria de escolha racional e da teoria de jogos, no qual o conflito é definido como um jogo de soma zero. (BERCOVITCH, 1984; ZARTMAN, 1985; FISCHER e URY, 1981; HARVARD PROGRAMME ON CONFLICT MANAGEMENT, s.d.).

A teoria de escolha racional e a teoria dos jogos são utilizadas para esboçar uma estratégia que permita um desenlace de ganho para todos. O conflito então se transforma de um jogo de soma zero em um jogo onde o ganho de uma das partes não significa necessariamente a perda da outra. Isto se atinge por meio de estratégias de barganha e negociações que sejam capazes de distribuir as perdas e os ganhos de forma eqüitativa. Ao se omitirem as causas subjacentes dos conflitos, procuram-se estratégias para atingir situações de ganho para todas as partes.

Esta visão não considera a erradicação do conflito como ponto culminante do processo, mas se foca na sua gestão (conflict management). Assim, o conflito deve ser manejado de forma construtiva para atingir um resultado satisfatório para as partes envolvidas. Persegue-se a eficiência nos resultados e a superação de situações de crise, mais do que a solução do conflito.

Nestes casos é essencial que se definam os interesses das partes, já que se procura a sua satisfação. A arbitragem é possível e, em particular, a participação de mediadores é muito bem-vinda, justamente para a transformação do conflito de soma zero em um conflito onde todas as partes ganham. Assim, processos de mediação e negociação são recomendados.

Os resultados desta abordagem podem ser limitados, se se considera que o sucesso se entende como o ganho sustentável para todas as partes, num prazo de tempo razoável e muitas vezes acordado a priori. Assim, por exemplo, manter a interrupção de hostilidades, evitar a invasão de propriedade privada, em suma, a volta ao status quo, é considerado como uma situação de ganho neste tipo de abordagem. No entanto, as causas subjacentes do conflito podem continuar intocadas. Desde esta perspectiva, tratase de soluções temporárias que podem, no futuro, reverter de novo para situações de conflito.

\section{Resolução de Conflitos}

Neste caso, o conflito se entende como o resultado de necessidades humanas insatisfeitas. Assim, as causas do mesmo estão nas necessidades subjacentes das partes e a sua resolução está em criar o entorno ou desenvolver as ações para sua satisfação. A resolução (conflict resolution) advoga a criação de processos que permitam a erradicação dos conflitos.

Nesta abordagem, consideram-se as causas subjacentes do conflito, isto é, o seu contexto social, político, econômico ou cultural e as situações de desigualdade de poder dominação e/ou dependência que o alimentam. O referencial é a Teoria de Necessidades Humanas (Human Needs Theory) desenvolvida por Burton e se utiliza da teoria dos jogos na busca de metodologias de resolução, só que em lugar de partir da visão de soma zero, o conflito é re-avaliado como um problema compartilhado com soluções que podem ser aceitáveis para todas as partes (BURTON, 1997; FISHER, 1983). A satisfação das necessidades leva em conta tanto as materiais, como alimentação e moradia, como as imateriais como justiça, 
desenvolvimento, segurança, reconhecimento e identidade.

Esta visão do conflito precisa de formas de condução que vão além dos arranjos e outras estratégias que enfatizam os interesses negociáveis das partes. Baseado nas necessidades que, em sentido estrito não são negociáveis, busca lidar com elas de forma sinérgica. As estratégias propostas para a resolução dos conflitos envolvem formas mais processuais que coercitivas, abrangendo atividades como a facilitação, as consultas com terceiros, os espaços de diálogo, como formas de adensar o nível de comunicação e informação entre as partes.

O objetivo é que as partes mergulhem na problemática e, conjuntamente, mediante a assistência de uma boa mediação de terceiros, procurem as soluções ou as formas de criação dos entornos necessários para a resolução do conflito. A idéia é tornar visíveis os pontos de interesse comum e os espaços de interseção de necessidades comuns, mediante a intensificação da comunicação e do diálogo. Só assim é possível visualizar as ações requeridas para satisfazer as necessidades das partes envolvidas.

\section{Transformação de Conflitos}

Uma terceira opção é aquela que considera, não apenas as condições que criam um entorno de conflito e as mudanças estruturais requeridas para sua resolução, mas também a promoção de condições para a criação de relações cooperativas (Burton e Dukes, 1990 apud MIALL, 2004). Esta abordagem é tratada na literatura sob o nome de transformação de conflitos (conflict transformation).

Esta visão tem como referencial teórico a Teoria dos Conflitos (Sociologia dos Conflitos), segundo a sua vertente não violenta desenvolvida por Sharp, Gandhi e King (REIMANN 2004) e seus proponentes mais ativos são Galtung, (1996) e Lederach $(1995,1997)$. Estes autores e ativistas partem de uma visão do conflito entendido como forma de luta não violenta em prol de justiça social. A ação não violenta trás à tona as tensões e contradições que são negadas ou disfarçadas socialmente. O conflito latente se manifesta mediante a "tensão construtiva não violenta” (McCarthy e Sharp,1997 apud REINMAN, 2004) na forma de mobilização popular. Assim, os grupos marginalizados social ou politicamente podem se mobilizar para dar visibilidade às suas reivindicações e procurar saídas às relações opressivas.

Visto assim, o conflito é produto primordialmente das estruturas sociais e políticas que fomentam a desigualdade, e lidar e resolver o conflito implica em procurar formas de empoderamento e de reconhecimento dos grupos marginalizados, como forma de começar o processo de transformação. Esta abordagem entende que os conflitos são positivos na medida em que são agentes de mudança social. Neste sentido, tem uma visão dinâmica e de longo prazo do conflito.

A conceitualização do conflito neste caso implica em reconhecer a necessidade de criar relações e desenvolver o diálogo e a cooperação entre atores muito desiguais pelo que, em lugar de dar centralidade à intervenção de terceiros, sem prescindir deles, atribui um papel muito ativo aos atores locais. Desta forma amplia o leque de atores que podem envolver lideres políticos, especialistas em resolução de conflitos, ONGs especializadas no tema, grupos indígenas, comunidades, etc. entendendo que todos têm um papel a cumprir no processo de construção das situações cooperativas gradativas e de longo prazo.

Assim, pode se pensar na busca da mudança de atitudes negativas entre as partes para aumentar a comunicação e cooperação entre elas. Ações tendentes à criação e/ou mudança da infra-estrutura institucional para o empoderamento e reconhecimento de grupos marginalizados são incentivadas, por considerar que isto promove situações de maior justiça social que incidem no entorno de transformação do conflito. Trata-se de criar as condições para que as desigualdades estruturais sejam enfrentadas com o objetivo de deslanchar um processo de reconstrução e reconciliação social de longo prazo. 
Esta visão entende que os conflitos precisam de mais do que da identificação de situações de ganho para as partes ou da resolução das suas necessidades imediatas. A própria arquitetura das relações das instituições ou entre as partes pode estar inserida num padrão conflituoso que vai além dos limites propriamente do conflito. A transformação do conflito é, portanto, um processo de engajamento -com e detransformação das relações, interesses, discursos, instituições, etc. que patrocinam a existência dos conflitos.

Estas três visões e estratégias se entendem e funcionam melhor quando se interpretam como complementares e não excludentes, podendo-se afirmar que as três são formas de intervenção e que cada uma tem o seu lugar no ciclo de vida do conflito. Podem, portanto, ser usadas de forma complementar em seus diferentes momentos.

\section{Modelo de interpretação}

A partir destas três interpretações pode se elaborar um modelo interpretativo que ajude também a compreender em quê etapa se encontra um determinado conflito e as suas alternativas de manejo. Parte-se de que as três interpretações acima colocadas formam um continuum que indica a evolução dos conflitos. (adaptado de AZAR, 1990).

Desta forma, na resolução (diagrama 1), o conflito aparece desde as condições de contexto, isto é, a formação sócio-histórica, as condições de governança e governabilidade, de poder, a legitimidades do Estado e das instituições, etc. que levam à falta de satisfação das necessidades e ao terreno do conflito. Este pode ser resolvido na medida em que se criem as condições (contexto) que melhorem e satisfaçam as necessidades reclamadas.

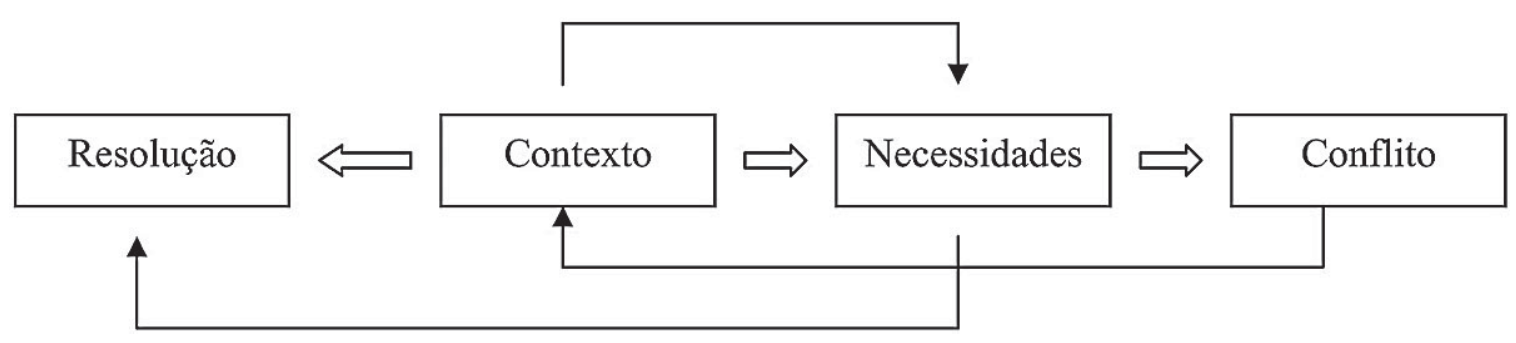

Na transformação (diagrama 2), também o conflito aparece nas condições de contexto e tendo de ser consideradas reivindicações de justiça social. Mas a perspectiva de criação de condições coopera- tivas leva, não apenas a resolução do conflito, mas à transformação das condições do contexto, desativando assim as razões estruturais do mesmo.

Desativação do Conflito

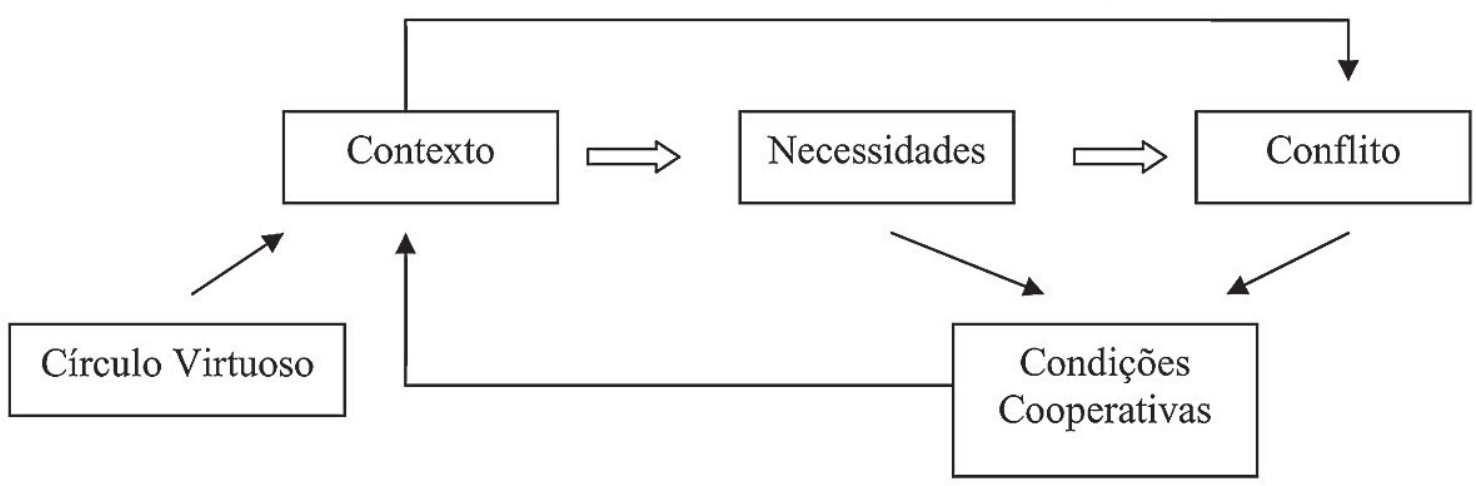

Sociedade \& Natureza, Uberlândia, 19 (2): 191-203, dez. 2007 
A resolução pode levar, se se tem uma visão de longo prazo e não apenas um ânimo eficientista e se conta com as instituições e os atores devidamente engajados, a uma transformação do conflito, onde se passa ao circulo virtuoso da desativação do conflito.

A gestão não permite este tipo de análise já que apenas depende da divergência nos interesses dos atores. No entanto, é de se anotar que este suposto não considera que os interesses dependem das condições (contextos) políticas, econômicas e sociais e, nessa medida, não são estáticos e que, por isso mesmo, não deveriam ser considerados independentemente dos outros fatores.

Os conflitos são dinâmicos, algumas vezes se ampliam, incorporando novos assuntos e atores e podem também se intensificar. Este dinamismo nos permite aferir que também podem transformar-se positivamente, na medida em que se melhoram as condições contextuais, se conte com boa mediação, surjam novos atores, etc.

A resolução e transformação dos conflitos reforçam a confiança da sociedade nas suas instituições, fazendo com que o contexto se fortaleça. Isto cria também condições para melhorar o sistema de governança. Quando os conflitos não são resolvidos, se transferem os danos das partes envolvidas para a sociedade. Isto atinge a capacidade cooperativa da sociedade como um todo, seu sistema de governança, a sua ordem econômica, e as relações sociais.
Pode levar a uma extrema distorção do funcionamento das suas instituições.

É importante reconhecer que existem grandes áreas de superposição entre as três formas de manejo dos conflitos. Por isso mesmo, os métodos também podem ser superpostos. A escolha de uma forma ou outra de manejo do conflito depende de uma série de variáveis, como a visão dos chamados a intervir, o seu treinamento e pano de fundo profissional e experiência de manejo dos conflitos, o conhecimento das diferentes opções ou os objetivos de intervenção no conflito. Se os objetivos correspondem a expectativas de curto prazo, muito provavelmente uma abordagem de gestão será apropriada, enquanto que em perspectivas de mais longo prazo, pode ser mais adequado pensar numa estratégia de transformação dos conflitos. O importante é ter consciência de que qualquer conflito, incluído os sócio-ambientais, pode ser abordado a partir de uma destas três opções ou mediante uma combinação delas.

A seguir mostramos, na tabela 1, as estratégias mais recomendados para o manejo dos conflitos em cada uma das três variantes.

É importante diferenciar os termos utilizados na tabela. A conciliação consiste na ação de uma parte neutra, sem interesses na disputa, de se comunicar com cada uma das partes separadamente com o propósito de reduzir as tensões e de acordar um processo de resolução do conflito. Já a negociação,

Tabela 1. Tipos de manejo de conflitos, características e estratégias de abordagem

\begin{tabular}{|c|c|c|c|}
\hline & Gestão & Resolução & Transformação \\
\hline Características & $\begin{array}{l}\text { Eficiência nos resultados } \\
\text { (curto, médio prazo). }\end{array}$ & Processual (médio, longo prazo). & $\begin{array}{l}\text { Processual } \\
\text { Estrutural (longo prazo). }\end{array}$ \\
\hline Estratégias & $\begin{array}{l}\text { Arbitragem, Negociação, } \\
\text { Mediação }\end{array}$ & $\begin{array}{l}\text { Facilitação } \\
\text { Conciliação } \\
\text { Mediação (terceiros sem poder de } \\
\text { decisão) } \\
\text { Criação de espaços de diálogo, } \\
\text { oficinas de resolução de conflitos }\end{array}$ & $\begin{array}{l}\text { Capacity building } \\
\text { Empoderamento } \\
\text { Coalições } \\
\text { Mediação (terceiros com poder de } \\
\text { decisão) }\end{array}$ \\
\hline
\end{tabular}


é o processo pelo qual as partes se encontram frente a frente para achar uma solução aceitável para o conflito. Na mediação, é necessário envolver uma terceira parte neutra no processo. No entanto, o mediador, ao contrário de um juiz, não tem poder de decisão sobre o que está em disputa. Ele apenas ajuda as partes a alcançarem seu próprio acordo. Por último, na arbitragem, as partes consensualmente submetem o caso para que seja avaliado e decidido por um terceiro com poder para emitir uma decisão, depois de negociarem sobre um conjunto de regras a seguir.

\section{Os conflitos sócio-ambientais}

A primeira coisa a ser dita é que os conflitos sócio-ambientais são cada vez mais freqüentes na realidade dos países da América Latina. Isto em parte é conseqüência da debilidade na implementação das políticas e esquemas de gestão disponíveis para a regulação do uso e acesso dos recursos naturais. Devem-se considerar também as dinâmicas sociais e econômicas que dizem respeito aos recursos naturais, cada vez mais complexas. É comum que o Estado se encontre sem recursos técnicos, administrativos e/ou financeiros para administrar conflitos em torno do uso dos recursos naturais nos quais existem, por exemplo, grandes assimetrias de poder.

De igual forma, o avanço das ações de desenvolvimento vai colocando desafios à gestão dos recursos na medida em que exerce pressão para seu uso, o que também pode gerar diferentes tipos de conflitos. Pode-se afirmar, então, que os conflitos são um importante sensor das relações sociais que se mobilizam ao redor do acesso e uso dos recursos naturais (LEFF, 1998).

O uso dos recursos naturais e os conflitos sócio-ambientais são um cenário de importantes repercussões para o futuro das nossas sociedades devido às mudanças que promovem em termos dos sistemas ecológicos e das propostas de desenvolvimento social.

Os conflitos sócio-ambientais são suscetíveis de serem manejados desde qualquer uma ou uma combinação das três formas de manejo de conflitos descritas antes. Assim, podem ser vistos como um assunto de gestão, onde a ênfase está na busca de resultados eficientes nos momentos de crise dos conflitos, mediante a procura de soluções de ganho para as partes envolvidas. Esta forma de gestão do conflito implica em não considerar as condições e fatores subjacentes do mesmo, apenas os seus sintomas.

Já a resolução dos conflitos leva a considerar os fatores contextuais que os promovem bem como mecanismos para a satisfação das necessidades daqueles envolvidos. As necessidades no caso dos conflitos sócio-ambientais seriam o acesso e uso de recursos naturais, como por exemplo, água ou terra, lenha, etc. ou a necessidade de reconhecimento ou participação no processo de tomada de decisão sobre o acesso e uso dos recursos de um grupo social.

A transformação dos conflitos leva implícita a idéia de construção de um processo de tomada de decisões conjunto entre as partes envolvidas que se comprometem, envolvem e participam da solução dos mesmos. A cooperação é a base do processo que deve apontar para a transformação de dinâmicas sociais que permitam arranjos mais justos de acesso e uso dos recursos naturais. Neste sentido, a criação de esquemas de gestão verdadeiramente participativos, de formulação de políticas públicas com a participação da sociedade, podem ser exemplos de processos de transformação de conflitos baseados na cooperação entre as partes. A ênfase está na construção de estruturas flexíveis e duradouras que dêem substância ao manejo construtivo do conflito e legitimidade às instituições. ${ }^{3}$

\footnotetext{
3 As metodologias de manejo surgem da inoperância e dificuldades do sistema tradicional de justiça de lidar com os conflitos. A comprovação da relação custo-benefício negativo neste tipo de procedimentos levou à busca de alternativas de solução. No entanto, a utilização de métodos alternativos de solução de conflitos tem enfrentado críticas também. Dentre elas, que pode constituir-se numa forma de privatização da justiça, devido a que se trata de um deslocamento das soluções desde a esfera do público à esfera do privado e, portanto, pode apresentar melhores resultados para setores privados de maior influência e deixar desprotegidos os interesses dos menos poderosos, assim como os públicos. (BOREL et al., 1999).
} 
Procura-se atingir um equilíbrio entre interesses diversos que logre uma internalização desta forma de se manejar o conflito. Isto cria uma cultura construtiva para sua transformação.

As formas de manejo expostas, têm, como é de se esperar, vantagens e desvantagens, porém, o sucesso ou fracasso da escolha vai depender da habilidade de se detectar oportunamente qual metodologia é mais propícia para um determinado momento do ciclo de vida do conflito. Isto é, o timing é fundamental.

No caso da gestão, argumenta-se que ao não considerar as causas do conflito, pode desconhecer elementos necessários para a desativação das crises. De outra parte, uma boa intervenção num momento de crise pungente pode significar o primeiro passo para a resolução de um conflito.

Quanto aos métodos de resolução e transformação, apresentam vantagens uma vez que potencializam formas mais democráticas de acesso e uso dos recursos naturais, fomentam formas mais responsáveis e sustentáveis de uso dos recursos e têm um potencial criativo que pode gerar novas formas de relações sociais e de manejo dos recursos. Por outro lado, suas limitações estão em que podem apresentar dificuldades em direcionar os processos, assim como em implementar mecanismos de planejamento e gestão dos recursos ou em equacionar as diferencias nos níveis de poder dos grupos envolvidos.

\section{Características dos conflitos sócio-ambientais}

Como já foi dito, os conflitos sócio-ambientais podem ser abordados segundo uma ou uma combinação de várias das opções de manejo delineadas antes. Em sua grande maioria, eles estão vinculados a um contexto mais amplo que diz respeito à realidade social, econômica e política da região ou país onde se desenvolvem. Desta forma, se entretecem temas ligados à distribuição da riqueza gerada pelo desenvolvimento, às expectativas de desenvolvimento de diferentes níveis territoriais, às políticas públicas que são o arcabouço institucional no qual ocorrem, aos espaços participativos da sociedade, aos projetos de desenvolvimento, etc. Por sua vez, esta complexidade de temas coloca uma multiplicidade de interesses sociais em contato e caracterizam o universo dos conflitos sócio-ambientais. Em seguida faremos uma descrição de algumas das características mais presentes neste tipo de conflitos segundo a literatura consultada (BOREL, et al, 1999; BLACKBURN, et al., 1999; SABATINI, et. al, 2000).

1. Os conflitos pelos recursos naturais como água, terra, florestas, etc. são ubíquos. No entanto, suas dimensões, níveis e intensidade variam. Eles podem ocorrer em diferentes escalas, desde a unidade familiar, a localidade, a região até a escala global. Também podem ocorrer em várias escalas simultaneamente.

2. Suas causas são variadas, sendo as mais comuns que os recursos naturais se encontrem em espaços interconectados, onde as ações de um indivíduo ou grupo podem gerar efeitos além da jurisdição onde foram originadas. De igual forma, os processos biofísicos e ecológicos se dispersam além das ações locais.

3. Os recursos são em geral compartilhados em espaços sociais onde se estabelecem relações complexas e desiguais entre uma ampla gama de atores sociais - empresários rurais, pequenos agricultores, minorias étnicas, agencias do governo, etc. Aqueles atores com maiores acessos ao poder são os que têm mais controle sobre as decisões ao redor do acesso e uso dos recursos.

4. Há diferentes formas como os recursos naturais são usados pelos grupos sociais. A terra, a água e as florestas não são apenas recursos materiais sobre os quais há concorrência, mas parte de uma forma de vida (de pescador, de agricultor, de pecuarista), de uma identidade étnica e/ou de papéis sociais. Esta dimensão é simbólica e se presta para que se explicitem lutas ao redor dos recursos naturais em termos sociais, ideológicos e políticos. Esta dimensão tem também incidência prática muito grande 
para o manejo dos conflitos, já que as perspectivas dos grupos sobre o significado dos recursos variam muito.

5. A complexidade destes conflitos pode implicar na necessidade de informação relacionada a aspectos legais, sociais, econômicos e científicos sobre o uso e manejo dos recursos naturais e das condições ambientais. As incertezas técnicas quanto às conseqüências de muitas das atividades humanas (desconhecimento do funcionamento de alguns sistemas naturais, ausência de indicadores de efeitos futuros, etc.) são um aspecto a considerar também. Por exemplo, muitos dos conflitos sócio-ambientais estão vinculados a grandes riscos, tanto naturais (desastres, extinção de espécies, deslizamentos, etc.) como sociais (perigos à saúde, deterioração da qualidade de vida, direitos humanos, sobrevivência econômica, etc.) (BLACKBURN, et al., 1999).

6. Como os conflitos sócio-ambientais encontram-se dentro do âmbito do interesse público, dada a relevância de alguns temas como a conservação, o desenvolvimento, o uso dos recursos, a saúde, etc. o Estado, que deve velar pela proteção do interesse geral de toda a sociedade, é um ator obrigatório neles (SABATINI, et. al, 1997).

7. Os atores envolvidos nestes conflitos são geralmente coletivos, como comunidades rurais, o governo e suas agências ou instituições, ONG locais ou internacionais, grupos de base organizados, empresas, camponeses, indígenas, igreja, grupos de pesquisa, dentre outros.

Os conflitos sócio-ambientais têm, portanto, múltiplas causas, algumas próximas e evidentes, outras distantes e não evidentes. É necessário por esta razão, desenvolver visões pluralistas que reconheçam as várias perspectivas dos atores e os efeitos simultâneos das diferentes causas dos conflitos para poder compreendê-los mais abrangentemente.

Dadas estas múltiplas dimensões, as formas de se lidar com o conflito no nível local, por exemplo, podem resultar em um esforço perdido em meio a fatores políticos, administrativos e financeiros em âmbitos mais abrangentes, que bloqueiam ou contradizem as decisões tomadas localmente. Muitas vezes o problema crítico não está tanto no nível micro, mas na incapacidade dos governos de servirem de contraparte útil às decisões tomadas localmente. Isto envolve sua capacidade de formulação e implementação de políticas públicas e de mudança e/ou formulação de um marco legal. Assim, o processo de tomada de decisão conta com uma multiplicidade de instâncias ou escalas.

Os atores apresentam algumas características:

1. Diferenças no nível de conhecimento e de informação

Os atores apresentam diferentes níveis de conhecimento e manejo da informação. Em geral, as comunidades rurais e camponesas têm pouco acesso à informação. Atores como empresários e governo têm mais acesso ao conhecimento e a informação.

\section{Diferenças de recursos e de poder}

Uma característica chave destes conflitos é a assimetria de poder entre os grupos envolvidos. (BOREL, 1999; SABATINI, et al.1997; FONTAINE, 2001). O poder expresso em termos políticos, econômicos e sociais.

\section{Diferenças nos aspectos culturais}

Cada grupo social tem uma forma de relação e apropriação dos recursos naturais, devido a aspectos culturais. As concepções sobre as formas de uso e aproveitamento dos recursos são diferentes, o que determina ações diferenciadas frente ao ambiente.

\section{CONCLUSÕES}

Todos os conflitos, dentre eles, os sócioambientais, podem ser manejados de alguma forma. 
No longo prazo, todos em teoria são solucionáveis, embora a solução tenha um custo diferente para cada caso. O manejo depende, em grande medida, de como o Estado tenha normatizado o uso e aproveitamento dos recursos naturais. No entanto, a natureza e magnitude da problemática sócio-ambiental, assim como a debilidade institucional do Estado, potencializam tanto a multiplicação como a escala dos conflitos. A incapacidade técnica, logística e administrativa para cumprir adequadamente com a função de controlar, fiscalizar e sancionar o cumprimento das normas e regras do acesso e uso dos recursos naturais são um fator fundamental neste cenário.

Frente a esta situação, uma série de metodologias e estratégias de manejo dos conflitos se colocam como alternativas para modificar estas situações e conduzir processos de mudança no acesso e uso dos recursos naturais. Aqui se sintetizam três estratégias, cuja escolha depende das características do conflito e da habilidade dos interventores de compreender seus pontos mais álgidos e seu ciclo de vida. São estratégias que apontam para diferentes resultados e que partem de diferentes noções de sucesso do manejo do conflito.

As particularidades dos conflitos sócio-ambientais também foram apontadas. Espera-se que estas alternativas sejam úteis para as ações de gestores de projetos sociais e sócio-ambientais em diferentes contextos e que ajudem a ordenar o universo de possibilidades na área de manejo e gestão de conflitos.

\section{AGRADECIMENTOS}

1. Este paper foi realizado com o apoio do projeto "Building Consensus on Access of Natural Resources in Brazilian Amazon - Projeto Diálogos" financiado pela União Européia e gerido por um consórcio de instituições, dentre elas, pelo Centro de Desenvolvimento Sustentável da Universidade de Brasília, a WWF e o CIRAD.durante 2006, a partir das oficinas de gestão de conflitos realizadas nas áreas de influência do projeto: Portal da Amazônia em 9,10 e 11 de Agosto de 2006 e Pará em 29, 30 e 31 de
Agosto de 2006. As duas oficinas foram coordenadas pelo Professor Elimar Pinheiro do Nascimento da UnB.

\section{BIBLIOGRAFIA CONFLITOS GERAL}

AZAR, E. The management of Protracted Social Conflicts. Aldershot:Dartmouth, 1990.

BERCOVITCH, J. Social Conflicts and Third Parties: Strategies of Conflict Resolution. Boulder: Westview, 1984.

BURTON, J. Conflict Resolution: Towards Problem Solving, 1997. Disponível em http:// www.gmu.edu/academic/pcs/burton.html. Acessado em 27 -08-2006.

FISHER, R. Third Party Consultation as a Method of Conflict Resolution: A Review of Studes. Journal of Conflict Resolution, 27, 2 1983, p. 301-334.

FISCHER R. e W. URY. Getting to Yes: How to Negociate without giving in. Londres: Arrow Books, 1981.

GAltung, J. Peace by Peaceful Means. Peace and Conflict, Development and Civilization. Londres: Sage Publications e Oslo: PRIO, 1996.

HARVARD PROGRAMME ON CONFLIT MANAGEMENT. s.d. Disponível em /www.hpcr.org/. Acessado em 14-08-2006.

LEDERACH, J. P. Preparing for Peace: Conflict Transformation Across Cultures. Nova York: Syracuse University Press, 1995.

LEDERACH, J. P. Building Peace. Sustainable Reconciliation in Divided Societies. Washington DC: United States Institute of Peace Press, 1997.

MIALL, H. Conflict Transformation: A multidimensional Task. In: FISHER, M e N. ROPPERS (ed). Berghof Handbook for Conflict Transformation, 2004. Disponível em: http://www.berghof- 
handbook.net/uploads/download/reimann handbook.pdf. Acessado em 12-07-2006.

NASCIMENTO, E. Os conflitos na Sociedade Moderna: uma Introdução Conceitual. In: BURSZTYN, M, A Difícil Sustentabilidade. Rio de Janeiro: Garamond, 2001.

REIMANN, C. Assessing the State of the Art in Conflict Transformation. In: FISHER, M e N. ROPPERS (ed). Berghof Handbook for Conflict Transformation, 2004. Disponível em: http:// www.berghof-handbook.net/uploads/download/ reimann_handbook.pdf. Acessado em 12-07-2006.

SCHMID, A. Early Warning of Violent Conflicts. In: SCHMID, A(ed.): Violent Crime and Conflicts. Milan: ISPAC - International Scientific and Professional Advisory Council of the UN Crime Prevention and Criminal Justice Programme, 1997.

SHARP, G. The politics of nonviolent action. Boston: Porter Sargent, 1973.

WALLACE R e A. WOLF. Contemporary Sociological Theory: Expanding Classical Tradition, (6ta Edição), New Jersey: Prentice Hall, 2006.

WEHR, P. Conflict Regulation. Boulder, CO: Westview Press, 1979.

WERH,P.The development of Conflict Knowledge. Disponível em: http://www.colorado.edu/ conflict/peace/essay/wehr7492.htm. Acessado em 20-07-2006

WEHR, P. Conflict Assessment. Comprehensive Assessment Guides. Disponível em: http:// spot.colorado.edu/ wehr/40GD1.HTM. Acessado em 17-07-2006.

ZARTMAN, I. W. Ripe for Resolution. Conflict and Intervention in Africa. Nova York: Oxford University Press, 1985.

\section{BIBLIOGRAFIA CONFLITOS SOCIOAMBIENTAIS}

ALONSO, A. e V. COSTA. Ciências Sociais e Meio Ambiente no Brasil: um balanço bibliográfico. BIB Revista Brasileira de Informações Bibliográficas em Ciências Sociais, ANPOCS, NO. 53, $1^{\circ}$ semestre de 2002, p. 35-78.

ASCELRAD, H. Conflitos Ambientais no Brasil. Rio de Janeiro: Reliume Dumará, Fundação Henrich Böll, 2004.

BARBANI Jr., O. Conflitos Socioambientais. Teorias e Praticas. I Encontro Associação Nacional de Pós Graduação e Pesquisa em Ambiente e Sociedade Indaiatuba, SP. Novembro, 2002. http://www. anppas.org.br/encontro/primeiro/encontro. Acessado em 02-07-2006

BLACKBURN, W. e W. BRUCE. Mediating Environmental Conflicts. Theory and Practice. Westport: Quorum Books, 1995.

BOREL, R e T. ROBERTSON. Conflictos Socioambientales en América Latina. Un Intento de Tipología, Mapeo y Análisis Comparado de Casos. Serie: Del Conflicto a la Colaboración.Red Mesoamericana de Manejo de Conflictos. Costa Rica, 1999.

FONTAINE, G. Sobre conflictos socio-ambientales en la Amazonía. El Estado y la gobernabilidad global, In: Documentos del Instituto Internacional de Gobernabilidad, Colección Gobernabilidad y Desarrollo Sostenible, 17, Barcelona, IIG, 2003. Disponível em http://www.iigov.org/gds/?p=17.

FUKS, M. Arenas de ação e debate público: conflitos ambientais e emergência do meio ambiente enquanto problema social no Rio de Janeiro. Dados, vol. $41, \mathrm{n}^{\circ} 1,1998$

LEFF, E. Saber Ambiental. Sostenibilidad, Racionalidad, Complejidad, Poder. México: Editorial Siglo XXI, 1998. 
LITTLE, P. Os conflitos socioambientais: um campo de estudo e da ação política. In: BURSZTYN, M. A Difícil Sustentabilidade. Rio de Janeiro: Garamond, 2001.

SABATINI C e SEPÚLVEDA S. Conflictos ambientales: entre la globalización y la sociedad civil. Santiago: CIMPA, 2000. 